\title{
Case Report: Incidentally diagnosed hemangioma of the right atrioventricular groove in an athlete [version 1; peer review: 1
}

\section{approved, 1 approved with reservations]}

\author{
Achour Asma (D1), Mezri Maatouk1, Ahmed Miladi (D1, Marouane Mahjoub (D2, \\ Mabrouk Abdelali(D1, Badii Hmida1, Ahmed Zrig1', Mejdi Ben Massoud (iD2, \\ Walid Mnari1 \\ ${ }^{1}$ Radiology Department, Fattouma Bourguiba University Hospital, Faculty of Medicine, Monastir University, Monastir, 5000, Tunisia \\ ${ }^{2}$ Cardiology Department, Fattouma Bourguiba University Hospital, Faculty of Medicine, Monastir University, Monastir, 5000, Tunisia
}

V1 First published: 01 Sep 2020, 9:1080

https://doi.org/10.12688/f1000research.24503.1

Latest published: 01 Sep 2020, 9:1080

https://doi.org/10.12688/f1000research.24503.1

\section{Abstract}

The purpose of this article is to illustrate a rare case of a pericardial hemangioma of the right atrioventricular groove of incidental discovery in a tennis player who presented with cough and dyspnea and was treated by surgical excision with a favorable outcome. We also report the role of cardiac magnetic resonance imaging (MRI) in the diagnosis and management of this pericardial tumor.

Keywords

Cavernous hemangioma, Cardiac tumors, Pericardium, Tamponade, Athletes

\section{Open Peer Review \\ Approval Status $\checkmark$ \\ 1 \\ version 1 \\ 01 Sep 2020

$?$
view \\ 1. Jean-Nicolas Dacher (D), Normandie University, Rouen, France \\ 2. Weikun Hu, Huazhong University of Science and Technology, Wuhan, China}

Any reports and responses or comments on the article can be found at the end of the article.

\section{Corresponding author: Achour Asma (doc.asma.achour@hotmail.com)}

Author roles: Asma A: Conceptualization, Formal Analysis, Investigation, Methodology; Maatouk M: Supervision, Validation; Miladi A: Visualization; Mahjoub M: Visualization; Abdelali M: Visualization; Hmida B: Visualization; Zrig A: Visualization; Ben Massoud M: Validation; Mnari W: Supervision, Validation

Competing interests: No competing interests were disclosed.

Grant information: The author(s) declared that no grants were involved in supporting this work.

Copyright: $\odot 2020$ Asma A et al. This is an open access article distributed under the terms of the Creative Commons Attribution License, which permits unrestricted use, distribution, and reproduction in any medium, provided the original work is properly cited.

How to cite this article: Asma A, Maatouk M, Miladi A et al. Case Report: Incidentally diagnosed hemangioma of the right atrioventricular groove in an athlete [version 1; peer review: 1 approved, 1 approved with reservations] F1000Research 2020, 9 :1080 https://doi.org/10.12688/f1000research.24503.1

First published: 01 Sep 2020, 9:1080 https://doi.org/10.12688/f1000research.24503.1 


\section{Introduction}

Cardiac hemangioma is a rare benign tumor $^{1}$ and pericardial localization is extremely $\operatorname{rare}^{2-4}$. It is usually asymptomatic, but it can be serious due to the risk of tamponade. We report the case of a pericardial hemangioma of the right atrioventricular groove in a young athletic patient who presented with cough and dyspnea and was diagnosed incidentally.

\section{Case report}

\section{Patient information and initial presentation}

A 31-year-old Caucasian female tennis player presented to the emergency department with dyspnea and dry cough for a few days. She had undergone surgery previously for a borderline ovarian tumor eight years ago. There was no history of cardiopulmonary disease, coronary artery disease, or other cardiovascular diseases. No abnormalities were found during the physical examination with no jugular venous distension.

\section{Diagnostic assessment}

A chest X-ray showed enlargement of the cardiac shadow suggestive of pericardial effusion (Figure 1). Transthoracic echocardiography confirmed a large circumferential pericardial effusion and showed a rounded, well defined pericardial hyperechoic lesion attached to the right atrioventricular groove. There was no right ventricular dysfunction.

A thoracic computed tomography (CT) scan was performed, which showed a large pericardial effusion and confirmed a

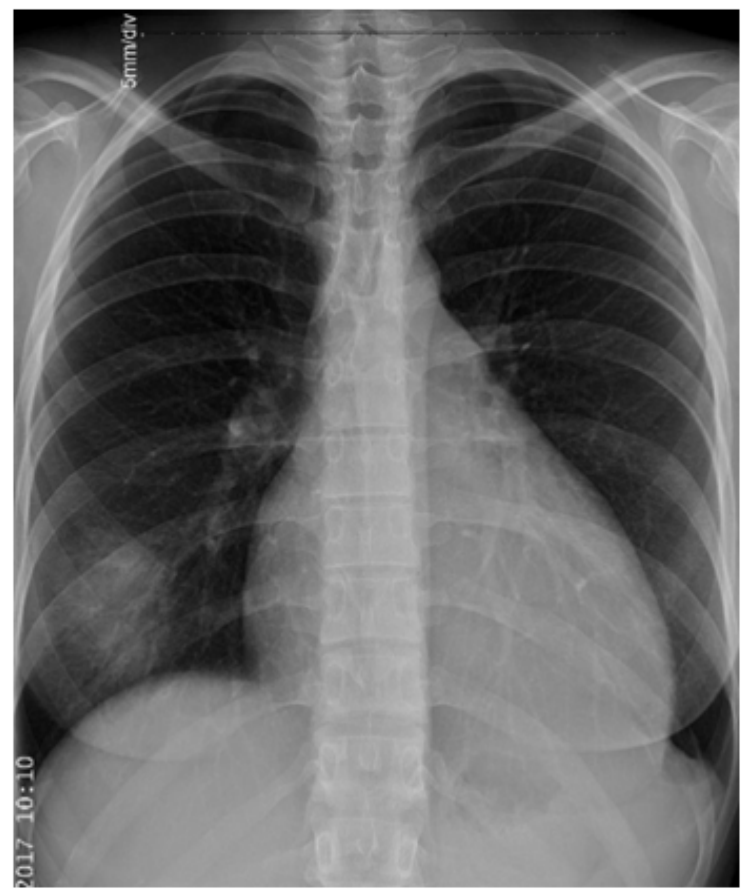

Figure 1. Chest X-ray shows a globular enlargement of the cardiac shadow. pericardial mass with homogenous contrast enhancement within the right atrioventricular groove (Figure 2).

Cardiac magnetic resonance imaging (MRI) confirmed the large pericardial effusion with a pedunculated ill-defined homogeneous hypointense mass on $\mathrm{T} 1$ and a hyperintense mass in the right atrioventricular groove with progressive enhancement after contrast administration on T2 (Figure 3).

A coronary angiography was performed, which showed tumor blush.

\section{Intervention}

The patient was referred to a cardiovascular surgery center to be operated on by an experienced cardiac surgeon. General anaesthesia was performed in supine position. Anaesthesia induction was performed by intravenous bolus of propofol $(2 \mathrm{mg} / \mathrm{Kg})$, tracrium $(0.5 \mathrm{mg} / \mathrm{Kg})$ and fentanyl $(2 \mathrm{mcg} / \mathrm{Kg})$. Anaesthesia maintenance was performed by isoflurane $1.5 \%$ in oxygen and continuous intravenous infusion of tracrium $(0.01 \mathrm{mg} / \mathrm{Kg} / \mathrm{min})$ and fentanyl ( $1 \mathrm{mcg} / \mathrm{kg} /$ hour $)$. Surgery was initiated by a median sternotomy. Initial examination showed no extension of the mass into the cardiac chamber. A safety total excision of the mass was done using cutting diathermy. Vascular, pericardial and sternal sutures were performed by polypropylene, vicryl and wire, respectively. The anatomopathological examination of the mass revealed conjunctive tumor proliferation, vascular differentiated and concluded with a diagnosis of cavernous hemangioma. Post-procedural medication included antibiotic therapy with cefazolin ( $1 \mathrm{~g}$ intravenously, twice a day) for 48 hours, preventive anticoagulation by low molecular weight heparin (Enoxaparin $0.4 \mathrm{ml}$ subcutaneously, once a day) and analgesic

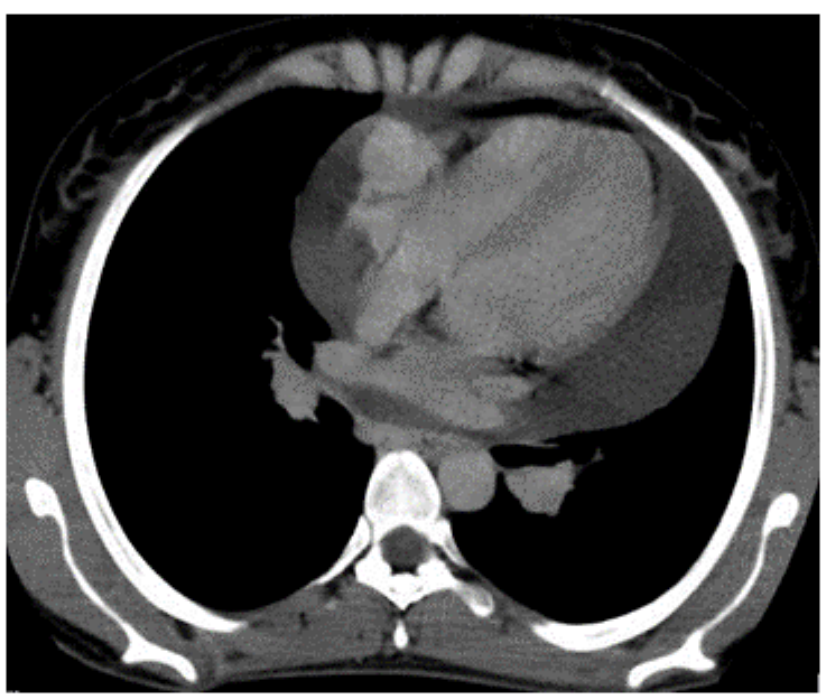

Figure 2. Thoracic computed tomography (CT) scan with contrast: right atrioventricular groove mass with homogeneous enhancement (arrow). 


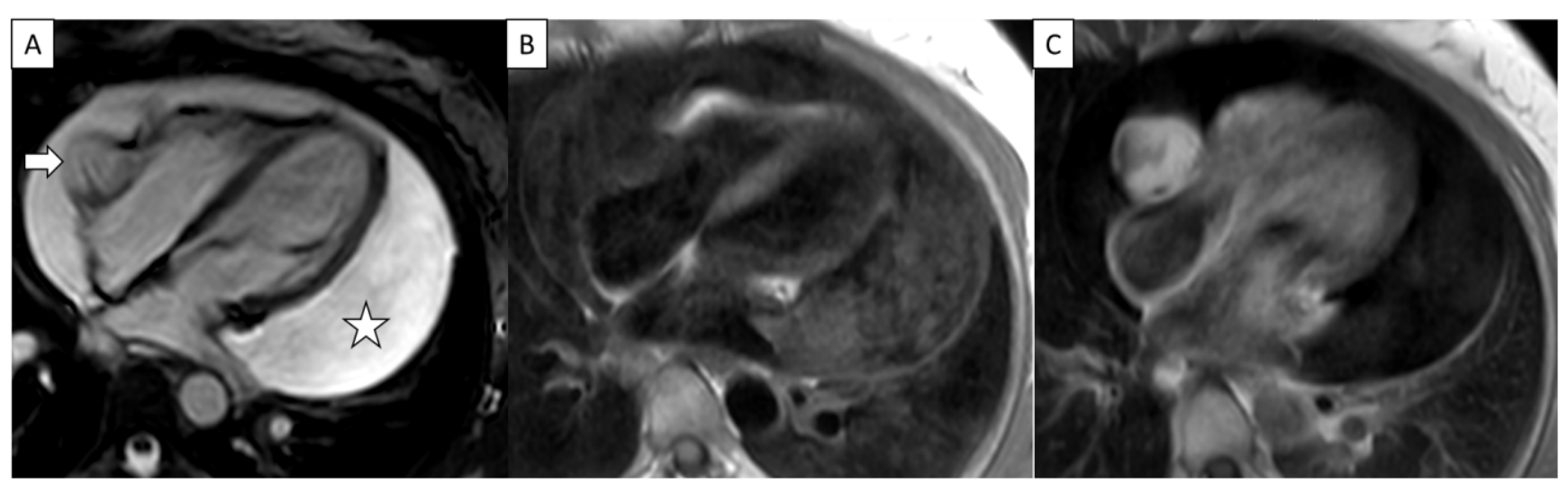

Figure 3. Cardiac MRI four-chamber view cine steady state free precession (A), black blood T1 weighted without (B) and after gadolinium administration (C): Rounded well defined homogenous hyperintense T2 hypointense T1 mass in right atrioventricular groove with homogenous enhancement after contrast administration (arrow). Note large pericardial effusion (star).

therapy by paracetamol (1 g intravenously, three times a day). Post-operative course was favorable and the patient was discharged after 72 hours.

\section{Follow-up}

Two months after surgery, the patient developed progressive dyspnea vomiting and precordial chest pain. CT scan found loculated left pleural effusion. Chest physiotherapy (one session a day) for two weeks and paracetamol (1 g orally, twice a day) for one week were prescribed with a favorable outcome. The patient remains well after two years of follow-up.

\section{Discussion}

Cardiac hemangiomas are rare benign vascular tumors and constitute only $2.8 \%$ of primary cardiac tumors ${ }^{1}$. Pericardial localization is extremely rare $^{2-4}$. Histopathologically, hemangiomas are characterized by benign proliferation of the endothelial cell lining of the blood vessel with increasing vascularization ${ }^{5}$.

Pericardial hemangioma is mostly asymptomatic. Clinical symptoms depend on location, size, and anatomic extension of the tumor $^{5}$. The most frequents symptoms are dyspnea, cardiac arrhythmia, murmurs, and heart failure. Tamponade due to pericardial effusion can also occur. Imaging is very useful for the diagnosis, localization, and extension of the tumor. CT scans with contrast can show enhancing foci at the arterial phase with diffuse or heterogeneous enhancement at the delayed phase. Small calcifications might be seen also $^{6}$. Cardiac MRI is a superior tool with a better contrast resolution ${ }^{5}$. Hemangiomas have an intermediate $\mathrm{T} 1$ signal with the same intensity as myocardium and a high $\mathrm{T} 2$ signal $^{7}$. The dynamic postcontrast acquisition shows nodular enhancement with progressive fill-in on delayed images ${ }^{8}$. Feeding vessel, tumor blush, and flow voids might be seen also ${ }^{1}$. The tumors are usually ill-defined with no local invasion. Differential diagnoses can be made with solid pericardial masses such as mesothelioma, sarcoma, lymphoma, or paraganglioma ${ }^{4}$. Surgical total excision is the treatment of choice for resectable tumors 9 . The use of radiotherapy, corticosteroids, and beta blockers have been reported in some cases ${ }^{1}$.

\section{Conclusion}

Pericardial hemangiomas are extremely rare benign vascular tumors whose prognosis depends on their location and size. Surgical excision constitutes the treatment of choice. Our case demonstrates the importance of cardiovascular MRI as a tool to evaluate the resectability of the tumor.

\section{Data availability}

All data underlying the results are available as part of the article and no additional source data are required.

\section{Consent}

Written informed consent for publication of their clinical details and clinical images was obtained from the patient.
1. Li W, Teng P, Xu H, et al.: Cardiac Hemangioma: A Comprehensive Analysis of 200 Cases. Ann Thorac Surg. 2015; 99(6): 2246-52. PubMed Abstract | Publisher Full Text

2. Reynen K: Frequency of primary tumors of the heart. Am J Cardiol 1996; 77(1): 107.

PubMed Abstract | Publisher Full Text
3. Kojima S, Sumiyoshi M, Suwa S, et al.: Cardiac hemangioma: a report of two cases and review of the literature. Heart Vessels. 2003; 18(3): 153-6. PubMed Abstract | Publisher Full Text

4. Gupta N: Intrapericardial hemangioma: a case report. J Clin Diagn Res. 2013; 7(1): 169-70.

PubMed Abstract | Publisher Full Text | Free Full Text 
5. Vargis RS, Phansalkar M, Padhi S, et al.: Pericardial Haemangioma: A Common Tumour in an Unusual Location: Case Report and Review of Literature. J Clin Diagn Res. 2017; 11(5): ED15-ED17.

PubMed Abstract | Publisher Full Text | Free Full Text

6. Restrepo CS, Vargas D, Ocazionez D, et al.: Primary Pericardial Tumors. RadioGraphics. 2013; 33(6): 1613-30.

PubMed Abstract | Publisher Full Text

7. Hrabak-Paar M, Hübner M, Stern-Padovan R, et al.: Hemangioma of the interatrial septum: CT and MRI features. Cardiovasc Intervent Radiol. 2011;
34 Suppl 2: S90-3.

PubMed Abstract | Publisher Full Text

8. Ediae J, Lim PS, Addonizio VP, et al.: Pericardial hemangioma taking origin from the posterior wall of the left atrium. Ann Thorac Surg. 2009; 87(6):

e54-6.

PubMed Abstract | Publisher Full Text

9. Esmaeilzadeh $\mathrm{M}$, Jalalian $\mathrm{R}$, Maleki $\mathrm{M}$, et al.: Cardiac cavernous hemangioma. Eur J Echocardiogr. 2007; 8(6): 487-9.

PubMed Abstract | Publisher Full Tex 


\section{Open Peer Review}

\section{Current Peer Review Status:}

\section{Version 1}

Reviewer Report 13 January 2021

https://doi.org/10.5256/f1000research.27029.r74537

(C) $2021 \mathrm{Hu}$ W. This is an open access peer review report distributed under the terms of the Creative Commons Attribution License, which permits unrestricted use, distribution, and reproduction in any medium, provided the original work is properly cited.

\section{Weikun Hu}

Department of Ophthalmology, Tongji Hospital, Tongji Medical College, Huazhong University of Science and Technology, Wuhan, China

This manuscript reported a rare case of pericardial hemangioma in an athlete, which showed potential clinical significance.

I recommend indexing after a minor revision.

The histological result and image of the tumor should be showed, as this is the important information for the diagnosis of hemangioma.

In addition, the post-operative cardiac MRI should also be showed, if the authors had done.

The patient had border-line ovarian tumor eight years ago. Were there any other general physical examinations that had been done before the surgery, such as PET-CT or specific markers of tumor? It is important to distinguish the possibility of tumor recurrence or metastasis.

The "diagnostic assessment" section (MR part) should be corrected as following: a hyperintense mass in the right atrioventricular groove with progressive enhancement after contrast administration on T1 (not T2 as shown in the manuscript).

The arrow is invisible in the Figure 2 as described in the figure legend.

\section{Is the background of the case's history and progression described in sufficient detail?} Yes

Are enough details provided of any physical examination and diagnostic tests, treatment given and outcomes? 
Is sufficient discussion included of the importance of the findings and their relevance to future understanding of disease processes, diagnosis or treatment?

Yes

Is the case presented with sufficient detail to be useful for other practitioners?

Yes

Competing Interests: No competing interests were disclosed.

I confirm that I have read this submission and believe that I have an appropriate level of expertise to confirm that it is of an acceptable scientific standard, however I have significant reservations, as outlined above.

Reviewer Report 07 September 2020

https://doi.org/10.5256/f1000research.27029.r70789

(C) 2020 Dacher J. This is an open access peer review report distributed under the terms of the Creative Commons Attribution License, which permits unrestricted use, distribution, and reproduction in any medium, provided the original work is properly cited.

\section{Jean-Nicolas Dacher}

Department of Radiology, Normandie University, Rouen, France

This is a nice case report of a rare condition that shows the importance of pre-operative imaging. I recommend indexing but a minor revision should be made regarding the description of MR findings.

In the "diagnostic assessment" section (MR part), the authors state that; "there is progressive enhancement after contrast administration on T2". This is misleading and should be corrected as usually contrast enhancement is not to be searched on T2-w imaging. I suppose that enhancement was detected either on post contrast T1-w imaging or on first pass perfusion (Saturation Recovery). This section should be re-written as well as the caption of Fig. 3 that is unclear in the present form.

I suggest the authors to re-use the excellent description from their discussion.

In the discussion please change the first sentence of the second chapter; the patient is asymptomatic, not the hemangioma.

Please delete the 's' at frequent (second chapter).

Is the background of the case's history and progression described in sufficient detail? Yes

Are enough details provided of any physical examination and diagnostic tests, treatment 


\section{given and outcomes?}

Yes

Is sufficient discussion included of the importance of the findings and their relevance to future understanding of disease processes, diagnosis or treatment?

Yes

Is the case presented with sufficient detail to be useful for other practitioners?

Yes

Competing Interests: No competing interests were disclosed.

Reviewer Expertise: Radiology

I confirm that I have read this submission and believe that I have an appropriate level of expertise to confirm that it is of an acceptable scientific standard.

Author Response 09 Sep 2020

Asma ACHOUR, Monastir University of Medicine, Tunisia., Monastir, Tunisia

Dear master and colleague,

Thank you for the interest you have shown in our topic.

I thank you for your relevant comments which will improve the quality of our manuscript.

Competing Interests: No competing interests were disclosed.

The benefits of publishing with F1000Research:

- Your article is published within days, with no editorial bias

- You can publish traditional articles, null/negative results, case reports, data notes and more

- The peer review process is transparent and collaborative

- Your article is indexed in PubMed after passing peer review

- Dedicated customer support at every stage

For pre-submission enquiries, contact research@f1000.com 